Computational Linguistics and Intellectual Technologies:

Proceedings of the International Conference "Dialogue 2020"

Moscow, June 17-20, 2020

\title{
COMPARATIVE ANALYSIS OF RHETORICAL AND ARGUMENTATIVE STRUCTURES IN THE STUDY OF POPULAR SCIENCE DISCOURSE
}

Kononenko I. S. (irina_k@cn.ru),

Sidorova E. A. (Isidorova@iis.nsk.su),

Akhmadeeva I. R. (ah.irishka@gmail.com)

A. P. Ershov Institute of Informatics Systems SB RAS, Novosibirsk, Russia

The proposed work is performed as a part of an on-going research project aimed at creation of discourse annotated corpus of popular science texts written in Russian. Annotation is carried out within the framework of a multi-level model of discourse, which considers the text from the perspective of genre, rhetorical and argumentative organization. We conduct a comparative study of the rhetorical and argument annotations, discuss their similarities and differences on the segment and structural levels and show them on the examples of standard schemes of reasoning described in D. Walton's theory of structured argumentation: "Argument from Expert Opinion", "Argument from Example", and "Argument from Cause to Effect". Special attention is paid to discourse markers registered during annotation as key indicators of discourse structure. We report the results of the experiment with argument indicator patterns, based on the list of rhetorical markers, and aimed at the extraction of "from Expert Opinion" arguments.

Key words: argument mining, argument indicator, indicator pattern, argumentation scheme, discourse annotation, corpus linguistics

DOI: $10.28995 / 2075-7182-2020-19-432-444$ 


\title{
СРАВНИТЕЛЬНЫЙ АНАЛИЗ РИТОРИЧЕСКИХ И АРГУМЕНТАТИВНЫХ СТРУКТУР ПРИ ИССЛЕДОВАНИИ НАУЧНО-ПОПУЛЯРНОГО ДИСКУРСА
}

\author{
Кононенко И. С. (irina_k@cn.ru), \\ Сидорова Е. А. (Isidorova@iis.nsk.su), \\ Ахмадеева И. Р. (ah.irishka@gmail.com) \\ Институт систем информатики им. А. П. Ершова \\ ИСИ СО РАН, Новосибирск, Россия
}

\begin{abstract}
В статье обсуждаются промежуточные результаты работы по созданию дискурсивно аннотированного корпуса научно-популярных текстов. Разметка осуществляется на основе многоуровневой модели представления дискурса, которая рассматривает текст с позиции жанровой, риторической и аргументативной организации. Проводится сравнительное исследование риторической и аргументативной аннотаций на примере фрагментов, представляющих типовые схемы рассуждения, основанные на теории Д. Уолтона. В рамках проводимого эксперимента на основе списка риторических маркеров разработан словарь шаблонов для извлечения схем аргументации «от эксперта» и проведено тестирование индикаторного подхода для анализа аргументации.
\end{abstract}

Ключевые слова: извлечение аргументации, индикатор аргументации, шаблон индикатора, схема аргумента, аннотирование дискурса, корпусная лингвистика

\section{Introduction}

The study of discourse involves a description of its structure in the form of related discourse units. One of the most famous models applied to this task is the Rhetorical Structure Theory (RST) and its modifications [6], [7], [8].

A particular role for discourse study is played by argumentation presented by the speaker or the author to convince the audience in her position. The theory of argumentation is growing in the framework of logic and philosophy, history and sociology, linguistics and psychology, computer science and artificial intelligence [4]. Over the past decade argument mining has been actively developing to solve the task of automatic extracting from text a sequence of statements (premises) that lead to a certain conclusion (thesis).

When analyzing argumentation presented in the text, it is necessary not only to extract arguments and chains of arguments that confirm or refute a certain thesis, but also to study the structure of each argument, its role and significance for the 
whole argumentation. The internal relations of the argument often coincide or can be built on the basis of the rhetorical relations of the RST model. To describe the various methods of reasoning, models or schemes of arguments are used [13], [19]. The most famous description of structured argumentation is the model of D. Walton [21], which defines about 60 basic argumentation schemes, each being the description of a specific reasoning pattern (inference form expressing the relations of premises and conclusion). The model has been used in a number of applications and tools for argument analysis and corpora annotation (OVA [5], Carneades [3], ArgDF).

So far, there exist only a few resources with annotated argumentative structures mainly over monologue texts in English. The best known is AIFdb, the former Araucaria corpus [14], which includes news articles, records of online debates. Resources are created in German: University of Darmstadt Corpus includes subcorpora of student essays [15], news texts and scientific articles; the Potsdam corpus contains a small set of microtexts on a given topic [10]. There exist projects for some other languages (Italian, Greek, Chinese). As for the Russian language, such resources, as far as we know, do not yet exist. In most cases, corpus annotation includes text segmentation with highlighting of argument units, markup of roles (premise, conclusion) and relations (support, attack), without matching the argumentation schemes on which the reasoning is based. An exception is Araucaria, where annotation of argumentative structure is related to particular argumentation scheme based on the theory of Walton [22].

In the past few years, studies have emerged in the field of automatic argument analysis that consider the potential use of existing text corpora with annotated discourse structure to facilitate the annotation of components and argumentative relations. The idea is to create a corpus of texts with multi-level annotation: along with the existing markup of rhetorical units and relations, texts are marked up with respect to the argument structure. In the presence of such a corpus, the task is to establish the relationship between rhetorical and argumentative structure of the text, the correlation of the components and relations between them in order to use existing resources and tools of discourse analysis to extract arguments. So, [9] describe the development and use in experiments of a two-level corpus of 112 short texts written in the genre of argumentative essays, and in [1], the material for annotation are scientific articles from the field of computer linguistics.

An important linguistic aspect of the process of discourse annotation is registration of discourse markers (discourse connectives)-language tools for structuring discourse, which play a key role in the process of understanding. Thus, argument indicators constitute keystones in the discourse, facilitating the identification and reconstruction of argumentative moves that are made in argumentative discussions and texts (see [20]). Argument indicators are language means (words, constructions) that serve as discourse clues in identifying the structure of argumentation: they help determine the presence of arguments in a given segment of text, reconstruct the connections between statements, relate the argument to a specific reasoning scheme.

The aim of this work is to study the correlations between rhetorical and argumentative structures in popular science discourse. The main research tools are annotated text corpus and dictionaries of indicators of rhetorical and argumentative relations. 


\section{Annotation model}

The proposed work was performed as part of an on-going research project aimed at creation of discourse annotated corpus of popular science texts written in Russian. It includes 68 articles on linguistics and 11 texts taken from the open corpus of RuRSTreebank [11], [17], [18]. Popular science discourse is defined as a way of transmitting scientific knowledge or innovation projects by the author-scientist (or a journalist as an intermediary) for their understanding by a mass audience.

Three levels are distinguished in the structure of the discourse, of which the first two correspond to the superstructure and relational structure in [6], [8].

1. Genre structure is responsible for the compositional and semantic organization of text at the highest level and depends on the text genre membership. This level involves a breakdown into meaningful compositional parts, such as chapters and paragraphs.

2. Rhetorical structure is responsible for organizing the text itself, transforming it from a simple sequence of formal segments into a single whole. It reflects the functional relationships existing between segments, called rhetorical relations.

3. Argumentative structure: represents the text as a means of reproducing the process of argumentation, highlighting the components of the argument field and the relationships between them (controversial thesis, arguments for or against). Argumentation is putting forward arguments in order to change or form some belief (position) of the other side [4].

To model and mark up the arguments, we used standard schemes (models) of reasoning from the Walton's compendium [22]. Consider a typical scheme of reasoning "Argument from Expert Opinion":

Major Premise: Source E is an expert in subject domain $S$ containing proposition A

Minor Premise: E asserts that proposition A is true (false)

Conclusion: A is true (false)

Subject-independent concepts in this scheme are the source of information E (it can be either a person, or, for example, an article in a journal), subject area $S$ and statement A. They are related by subject-independent relations be_expert ( $E, S$, true), belong_to (A, S, true) and assert (E, A, true), be_true (A, true / false).

In addition to the above three types of annotation (genre, rhetorical and argumentative), another one is important-that concerning indicators of rhetorical relations or aspects of argumentation. When annotating arguments, the indicators are marked up at the same time, which allows us to automatically build a dictionary of indicators.

\section{Study of correlations between rhetorical and argument annotation}

For the comparative study, a subcorpus of 11 rhetorically annotated texts was taken from the Ru-RSTreebank and provided with argument annotation. 


\subsection{Segment-level comparison}

The basis of both rhetorical and argument annotation is segmentation into elementary discourse units (EDUs). These units are sentences, clauses or minimal text spans which have propositional content including nominalized propositions and prepositional phrases with the meaning of cause, effect, concession, contrast (for example EDU 32 in Fig. 1b).

In the rhetorical annotation process EDUs are combined into larger DUs which can be used in rhetorical relations alongside with EDUs. This iterative process provides the construction of RST trees.

The argument annotation process is different.

Firstly, there is no unit enlargement procedure since the semantics of the generated graph chains is associated with meaningful aspects of the argumentative relations, and not with the structural ones, as it happens in the process of segment merging in rhetorical structures.

Secondly, despite the fact that a definition of argumentation units (ADUs) is based on discourse ones, i.e. ADU is an EDU representing a separate (independent) component of the argument, however, there is no one-to-one correspondence:

1. EDUs not relevant to the argumentation are ignored. For example, spans of text containing introductory or factual information not used as a premise.

2. Adjacent EDUs are combined into one ADU if they do not represent independent components of the argument: in Fig. 1 segments 33 and 34 connected by Elaboration relation are combined.

a)

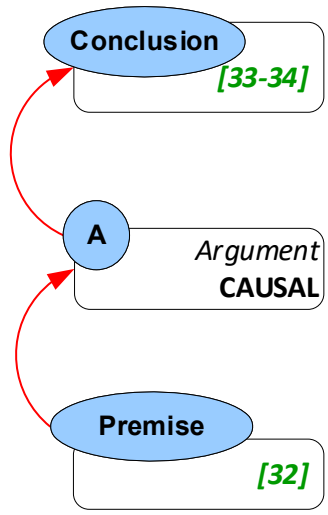

b)

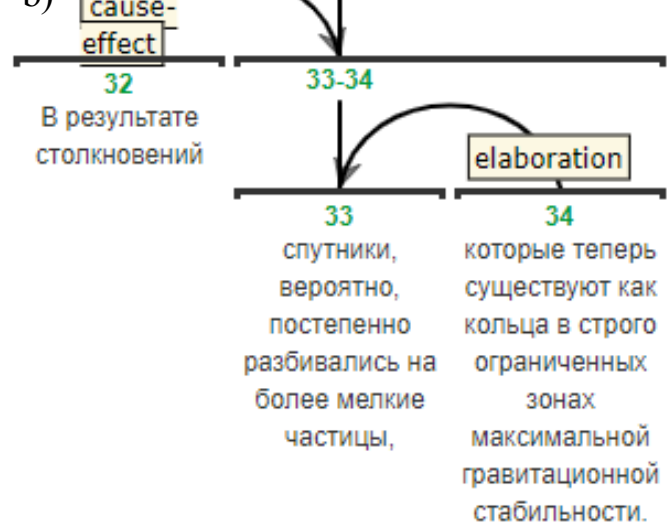

Text: As a result of collisions [32], the satellites were likely to gradually break into smaller particles [33], which now exist as rings in strictly limited zones of maximum gravitational stability [34].

Fig. 1. Comparison of segmentation with argument

(a) and rhetorical (b) annotation

A similar merge is possible for segments connected by Joint relation (segments 102-103 in Fig. 2). 
a)

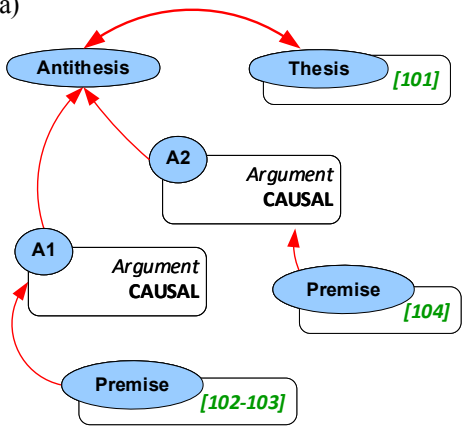

b)
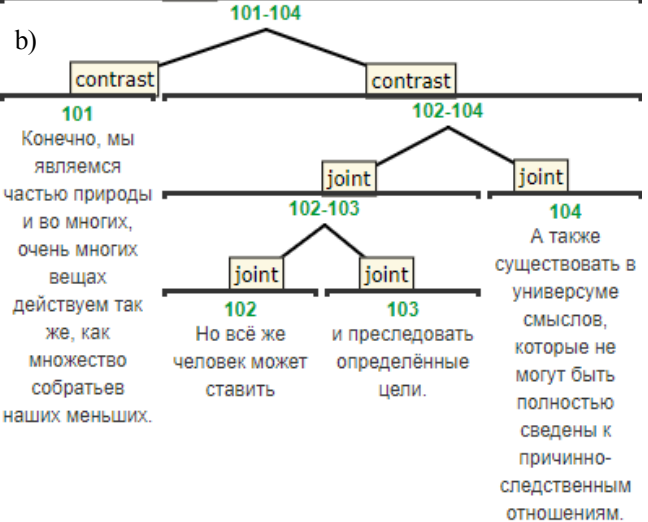

Text: Of course, we are part of nature, and in many, many things we act in the same way as many of our lesser brethren [101]. But still, a person can set [102] and pursue certain goals [103]. And also exist in a universe of meanings that cannot be completely reduced to cause-and-effect relationships [104].

Fig. 2. Comparison of segmentation with argument (a) and rhetorical (b) annotation

a)
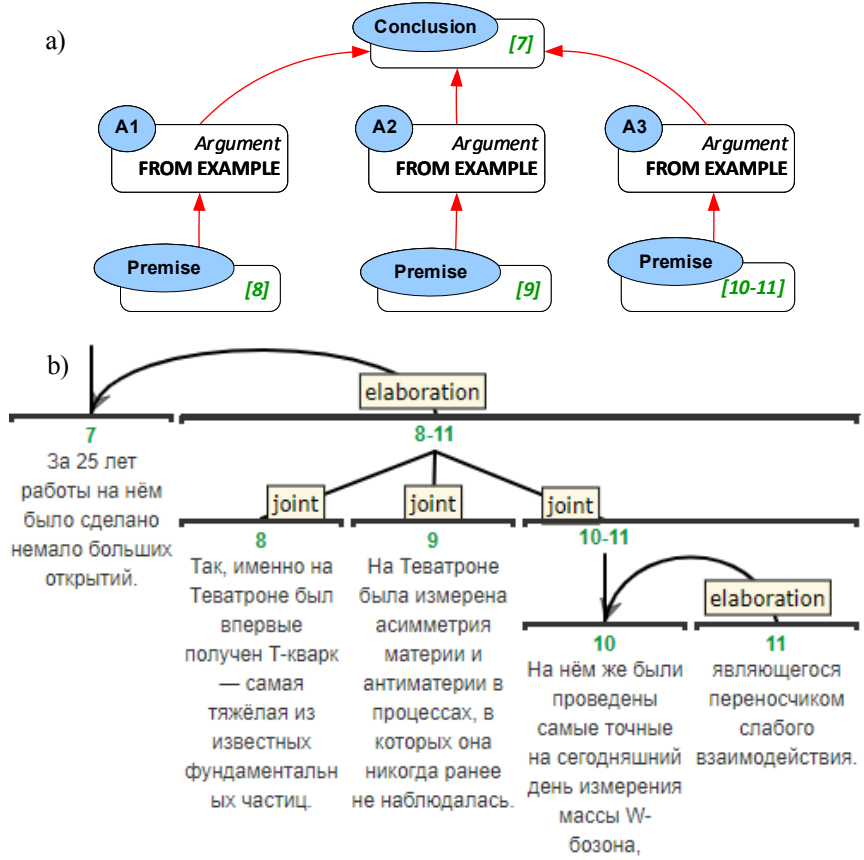

Text: Over 25 years of work on it (Tevatron), many great discoveries have been made. [7] So, it was at the Tevatron that the first top quark was obtained - the heaviest known fundamental particle.[8] At the Tevatron, the asymmetry of matter and antimatter was measured in processes in which it was never previously observed.[9] On it, the most accurate measurements of the mass of the $W$ boson, [10] which is a carrier of weak interaction, were made to date.[11]

Fig. 3. Comparison of segmentation with argument (a) and rhetorical (b) annotation 
In contrast to the latter, segments 8-11 connected by Joint relation in Fig. 3 are not united, since each member of the Joint corresponds to an independent argument that implements the argumentation scheme "From the Example".

3. The correspondence between rhetorical and argumentation units is also broken in case of arguments appealing to the Knower, in particular, to the Expert (see Fig. 4). In the rhetorical structure there are two adjacent EDUs connected by the Attribution relation. In the argumentative structure the thesis segment is nested in the minor premise segment and this premise is the result of merge of adjacent EDUs-according to the "Argument from Expert Opinion" scheme presented in section 1.
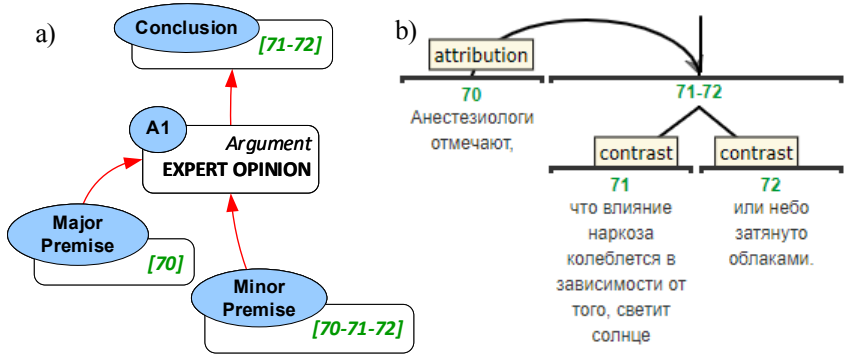

Text: Anesthetists note [70] that the effect of anesthesia varies depending on whether the sun is shining [71] or the sky is cloudy [72].

Fig. 4. Comparison of segmentation with argument (a) and rhetorical (b) annotation

4. Two EDUs connected by the Same_unit relation are combined in one ADU to represent a discontinuous segment: segments 31, 33 (Fig. 5a) and segments 99, 101 (Fig. 5b).

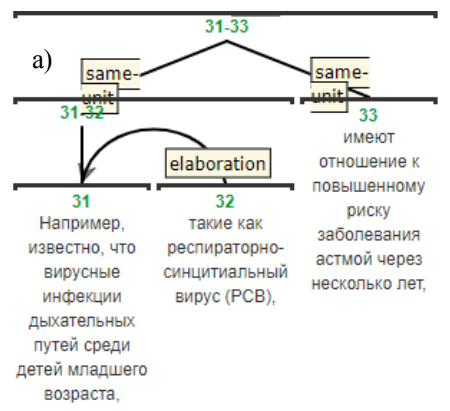

Text: For example, viral infections of the respiratory tract in young children [31], such as the human respiratory syncytial virus (HRSV)[32], are known to be associated with an increased risk of asthma after a few years [33]

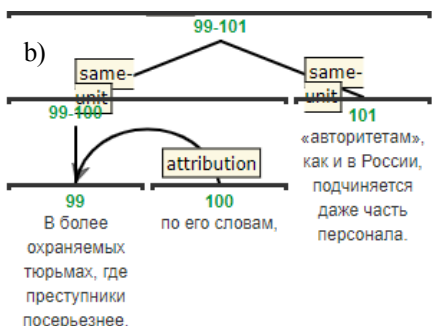

посерьезнее,

Text: In more secure prisons, where criminals are more serious [99], according to him [100], even part of the staff obeys the "authorities», as in Russia [101].

Fig. 5. Merging segments into one ADU to represent discontinuous statements

5. An EDU containing homogeneous groups is split up if the recovered propositions are considered to correspond to independent arguments (segments 102 and 103 in Fig. 2). 
And finally, the treatment of indicators of discourse relations is different. For example, in rhetorical annotation indicators are always included in the DUs, while most of argument indicators (так как 'because'; то, что 'the fact that'; следовательно 'therefore', etc.) are excluded from ADU as they do not belong to the propositional content of ADU that appears in the role of premise or conclusion of the argument. Thus, the boundaries of text fragments acting as discourse units are different.

\subsection{Comparison of rhetorical and argument indicators}

In the Penn Discourse Treebank (PDTB) discourse connectives are considered as binary predicates that express certain semantic relationships between sentences, events and states [12]. In the RST, subject matter relations are opposed to presentational relations whose intended effect is to increase some inclination in the reader, such as the desire to act or the degree of positive regard for, belief in, or acceptance of the nucleus of the rhetorical relation. Considering the linguistic theory of argumentation of Ancombre and Ducro [2], in which two classes of argument markers (connectors and operators) are distinguished, as well as the concept of presentational rhetorical relation, it can be assumed that in argumentation (as a special case of discourse sequence) a representative subset of rhetorical discourse markers is used as argument indicators.

Heterogeneous set of discourse connectives is usually considered to be indicators of discourse structure. It traditionally includes non-significant lexical units, or functional words and phrases: subordinating conjunctions, coordinating conjunctions, adverbs, prepositional phrases, parenthetical words, particles, etc. Recent studies of discourse indicators [16], [17] take into account not only traditional discourse connectives, but also grammatical time, punctuation marks and their combinations, as well as content words and constructions based on them [18].

Connectors that express presentational rhetorical relations signal semantic-ontological relation between statements and indicate the following pragmatic aspects of argumentation:

- strength of the argument (по-видимому 'seemingly');

- inference relation between two statements (следовательно 'therefore');

- role of the statement in the inference relation: Premise (поскольку 'since') vs. Conclusion (поэтому 'for that reason');

- type of argumentative relation: Support (например 'for example') vs. Attack (однако 'however');

- structural type of argumentation: Multiple (тем более что 'all the more so that') vs. Serial argumentation (в подтверждение этому 'in confirmation of this').

As for operators (particles such as именно 'јust', только 'опly', еще 'yet', почти 'almost', по крайней мере 'at least', etc.), they usually don't signal about rhetorical relations (as there is no relation of two explicit propositions), but clearly give an argumentative orientation to the statement:

(1) [Быстрее всего обновляется лексический фонд], так как только [он непосредственно связан с материальным миром]. Диалектная фонетика, грамматика и синтаксис сохраняются очень хорошо. 
[The lexical fund is updated most quickly], since only [it is directly connected with the material world]. Dialectal phonetics, grammar and syntax persist very well.

Annotators of the Ru-RSTreebank took account of rhetorical markers and compiled their lists, which include not only functional words, but also content words and constructions with them: причина стать 'reason to bесоте'; являться результат 'be the result'; как стать известно 'as (it) bесоте knоwn'; намекать на то, что 'hint at the fact that'. However, words and phrases in the list set too general contexts. For example, there are markers formed on the basis of the speech verb говорить 'speak/tell/say': X говорит о Y 'X talks/speaks about Y'; говори 'speak/tell/say'; говоpuть о том, что 'to show/suggest that/ be indicative of'; mот факт, что ... говорит о том 'the fact that...shows that'; иначе говоря 'in other words'; не говоря уже о 'tо say nothing of'; точнее говоря 'to be more exact'. As analysis shows, the consideration of speech verbs as indicators of the Attribution rhetorical relation gives in case of the verb говорить and some other verbs (подтверждать 'confirm', признавать 'recognize') up to 70 percent of noise:

(2) По-разному говорят представители различных профессий, люди разных возрастов и интересов, жители разных городов.

Representatives of various professions, people of different ages and interests, residents of different cities speak differently.

The specification of the indicator in the form of a pattern with the core speech verb and a sentential actant marker umo 'that' or a citation marker for direct speech allows to increase the precision in identifying the Attribution relation:

(3) Гениальный дипломат Шарль Морис Талейран говорил, что язык нам дан для того, чтобы скрывать наши мысли.

The brilliant diplomat Charles Maurice Talleyrand said that language was given to us in order to hide our thoughts.

To recognize such constructions, the following pattern is appropriate:

speech_activity_that $=[<$ Sem:speech_activity $>$, s/, , umo 'that']

A more precise definition of this pattern with addition of the lexical class Expert as a source of information allows us to present the indicator of the "from Expert Opinion" argument scheme:

[begin: <Sem:expert>, end: speech_activity_that]

\subsection{Experimental study of argument extraction by indicator patterns}

An experimental study of indicator patterns was carried out using training and test collections. The training collection consisted of 68 popular science articles on linguistics (more than 64 thousand word uses). Based on a dictionary of rhetorical markers and annotated corpus, patterns for extracting arguments were developed. The final dictionary of indicators included constructions for cases of expressing an authoritative opinion ("Argument from Expert Opinion"), presented as literal quotation (direct speech) or indirectly (using speech or mental predicates with sentential actants). The 
lexical dictionary contained 114 units (90 nouns and 24 noun phrases) of the expert class, as well as 78 speech, 14 mental and 9 predicates of intellectual activity.

The evaluation of the quality of extracting arguments by the indicator method was carried out on the test collection, which included 877 popular science articles taken from open sources (about 2,880 thousand word uses). Table 1 presents experiment results.

Table 1. Evaluation of the quality of argument extraction

\begin{tabular}{|l|r|r|}
\hline & Training collection & Test collection \\
\hline Total & 275 & 2,694 \\
\hline Incorrect (0) & 10 & 509 \\
\hline No arguments (1) & 58 & 414 \\
\hline Conditionally correct (2) & 36 & 528 \\
\hline Correct (3) & 168 & 1,243 \\
\hline Precision & $74.18 \%$ & $65.73 \%$ \\
\hline
\end{tabular}

In the evaluation, the following scale was used:

0 - the extracted text fragment does not match target construction;

1 - fragment contains no argument;

2 - target construction is matched but the presence of argument requires clarification in a wider context;

3 - target construction and argument are extracted.

When evaluating precision, answers scored 2 and 3 were considered correct.

The analysis of the experiment results revealed the following reasons for incorrect identification of arguments:

a) lack of structural correspondence due to syntactic ambiguity or punctuation marks usage (dash, quotes);

b) lexical ambiguity: actualization of the non-speech meaning of the predicate (the speech one is often non-primary, e.g. продолжить 'to continue', говоpumb 'to indicate'), homonymy of the type "science-specialist" (cтатистикаcmamucmuk 'statistics-statistician');

c) no proposition in the actant of the predicate (actant position filled by the object)

(4) Исследователь жизни поэта учился в московском Университете дружбы народов и написал книгу о Пушкине

Researcher of the poet's life studied at the Peoples' Friendship University in Moscow and wrote a book about Pushkin

or incomplete proposition in the actant (indirect question)

(5) О том, какудержать баланс между изменчивостью и сохранением идентичности, и кто играет, рассказал Михаил Штудинер, кандидат фил. наук,

How to maintain a balance between variability and preservation of identity, and who plays, said Mikhail Shtudiner, Ph.D.; 
d) lack of reference annotation for events and authoritative persons (experts) in case they are referred to by name or by anaphoric pronoun

(6) "Ngram Viewer позволяет получить статистику любому желающему и проводить собственные исследования",-рассказывает Валерий Соловьев. "Ngram Viewer allows you to get statistics for anyone and conduct their own research" says Valery Soloviev.

\section{Conclusion}

In the paper we presented an approach to modeling and studying the arguments found in popular science literature. The approach is based on the comparative analysis of the rhetorical and argumentative discourse structures. A large number of correlations makes it possible to apply recent developments in the field of rhetorical structures to the analysis of argumentation, in particular, to the construction of a dictionary of argument indicators.

In the course of the experiment based on the list of rhetorical markers, a dictionary of indicator patterns was developed to extract typical reasoning schemes "from Expert Opinion", and an indicator approach was tested for analysis of argumentation.

Further research focuses on the comparison of argumentative and rhetorical structures with the view of revealing correspondences between argumentative chains and rhetorical trees.

\section{Acknowledgment}

The research has been supported by Russian Foundation for Basic Research (Grant No. 18-00-01376 (18-00-00889)).

\section{References}

1. Accuosto P., Saggion H. (2019), Discourse-driven argument mining in scientific abstracts, 24th International Conference on Applications of Natural Language to Information Systems NLDB 2019, Salford, UK, pp. 182-194.

2. Anscombre J.-C., Ducrot O. (1983), Argumentation in the language [L'argumentation dans la langue], Brussels.

3. Gordon T. F., Walton D. (2006), The Carneades argumentation framework-using presumptions and exceptions to model critical questions, Proc. of the 2006 Conf. on Computational Models of Argument: Proceedings of COMMA 2006, Amsterdam, Vol. 6, pp.195-207.

4. Ivin A. A. (2017), Argumentation in the processes of communication. Pro et contra [Argumentatsiya v protsessakh kommunikatsii. Pro et contra], Prospect, Moscow.

5. Janier M., Lawrence J., Reed C. (2014), OVA+: An argument analysis interface, Computational Models of Argument: Proc. of COMMA 2014, Amsterdam, Vol. 266, pp. 463-464. 
6. Litvinenko A. L. (2001), Description of the structure of discourse in the context of the theory of Rhetorical Structure: application in Russian material [Opisaniye struktury diskursa v ramkakh Teorii Ritoricheskoy Struktury: primeneniye na russkom materiale], Computational Linguistics and its Applications: Proceedings of the International Seminar "Dialog 2001" [Komp'yuternaya Lingvistika i yeye prilozheniya: Trudy Mezhdunarodnogo Seminara "Dialog 2001”], Aksakovo, pp. 159-168.

7. Mann W. C., Thompson S. A. (1988), Rhetorical Structure Theory: Toward a Functional Theory of Text Organization, Text, 1988, 8(3).

8. Mann W., Matthiessen C., Thompson S. A. (1992) Rhetorical structure theory and text analysis, Discourse Description, Amsterdam, Benjamins, pp. 39-78.

9. Musi E., Alhindi T., Stede M., Kriese L., Muresan S., Rocci A. (2018), A Multi-layer Annotated Corpus of Argumentative Text: From Argument Schemes to Discourse Relations, Proceedings of the Eleventh International Conference on Language Resources and Evaluation (LREC'2018), Miyazaki, Japan, pp.1629-1636.

10. Peldszus A., Stede M. (2016), An annotated corpus of argumentative microtexts, Argumentation and Reasoned Action: Proceedings of the 1st European Conference on Argumentation, London, College Publications, Vol. 2, pp. 801-816.

11. Pisarevskaya D., Ananyeva M., Kobozeva M., Nasedkin A., Nikiforova S., Pavlova I., Shelepov A. (2017), Towards building a Discourse-annotated corpus of Russian, Computational Linguistics and Intellectual Technologies: Proceedings of the International Conference "Dialogue 2017", Moscow, pp. 194-204.

12. Prasad R., Miltsakaki E., Dinesh N., Lee A., Joshi A., Robaldo L., Webber B. (2007), The Penn Discourse Treebank 2.0 Annotation Manual, Technical Report 203, Institute for Research in Cognitive Science, University of Pennsylvania.

13. Reed C., Walton D. (2003), Argumentation schemes in argument-as-process and argument-as-product, Proc. of Conference Celebrating Informal Logic, OSSA Conference Archive 75, University of Windsor, Windsor, Ontario.

14. Reed C., Rowe G. (2004), Araucaria: Software for argument analysis, diagramming and representation, International Journal on Artificial Intelligence Tools, Vol. 13(4), pp. 961-979.

15. Stab C., Gurevych I. (2014), Identifying Argumentative Discourse Structures in Persuasive Essay, Conference on Empirical Methods in Natural Language Processing (EMNLP), Doha, Qatar, pp. 46-56.

16. Taboada M., Das D. (2013), Annotation upon Annotation: Adding Signalling Information to a Corpus of Discourse Relations, Dialogue and Discourse, 4(2), pp. 249-281.

17. Toldova S., PisarevskayaD., Ananyeva M., Kobozeva M., Nasedkin A., Nikiforova S., Pavlova I., Shelepov A. (2017), Rhetorical relations markers in Russian RST Treebank, Proceedings of the 6th Workshop on Recent Advances in RST and Related Formalisms. Santiago de Compostela, Spain, pp. 29-33.

18. Toldova S., Pisarevskaya D., Vasilyeva M., Kobozeva M. (2018), The cues for rhetorical relations in Russian: "Cause-Effect" relation in Russian Rhetorical Structure Treebank, Computational Linguistics and Intellectual Technologies: Papers from the Annual International Conference "Dialogue", pp. 747-761. 
19. Toulmin S. (2003) The Uses of Argument, Cambridge University Press, Cambridge.

20. Van Eemeren F. H., Houtlosser P., and F. Snoeck Henkemans (2007), Argumentative Indicators in Discourse: A Pragma-Dialectical Study, Dordrecht, Springer.

21. Walton D. (2009) Argumentation theory: A very short introduction, Argumentation in Artificial Intelligence, Springer, Boston, pp. 1-22.

22. Walton D., Reed C., Macagno F. (2008) Argumentation schemes, Cambridge University Press. 